\title{
Articles
}

\section{Biochemical and NMR Characterization of MTH1880 Mutant Proteins for Folding-Unfolding Studies}

\author{
Heeyoun Kim, ${ }^{a}$ Sooyoung Ryu, ${ }^{a}$ Ji-hye Yun, Suhkmann Kim, ${ }^{\dagger}$ Iksoo Chang, ${ }^{\dagger}$ and Weontae Lee ${ }^{*}$ \\ Department of Biochemistry, College of Life Science and Biotechnology, Yonsei University, Seoul 120-749, Korea \\ *E-mail:wlee@spin.yonsei.ac.kr \\ ${ }^{\dagger}$ Department of Chemistry and Chemistry Institute for Functional Materials, Pusan National University, \\ Busan 609-735, Korea \\ ${ }^{\ddagger}$ Creative Research Initiatives Center for Proteome Biophysics, Department of Physics, Pusan National University, \\ Busan 609-735, Korea \\ Received July 15, 2010, Accepted September 16, 2010
}

\begin{abstract}
MTH1880 is a hypothetical protein derived from Methanobacterium thermoautotrophicum, thermophilic methanogen. The solution structure determined by NMR spectroscopy showed that it has a novel $\alpha+\beta$-fold with a highly acidic ligand binding pocket. Since MTH1880 maintains its ultra-stable structural characteristics at both high temperature and pressure, it has been considered as an excellent model for studying protein folding. To initiate the structural and folding study of MTH1880 in proving its unusual stability, we performed the site directed mutagenesis and biochemical analysis of MTH1880 mutants. Data from circular dichroism and NMR spectroscopy suggest that the point mutations perturbed the structural stability of protein even though the secondary structure is retained. This study will provide the useful information in understanding the role of participating residues during folding-unfolding process and our result will be used in designing further folding experiments for hyper-thermopile proteins like MTH1880.
\end{abstract}

Key Words: MTH1880, Protein folding, NMR, Circular dichroism

\section{Introduction}

Understanding the folding-unfolding mechanism for a protein with novel fold still remains one of the challenging areas in structural biology. Recent structural genomics project which determines three-dimensional structures of proteins with unknown functions has been considered as a critical step for both expanding a protein fold space and leading to its biochemical and molecular function. ${ }^{1,2}$ In case of a novel fold protein, the folding-unfolding mechanism becomes of interest in understanding folding pathways of a new structure family. ${ }^{3-7}$ It has been reported that protein folding process has been found to be highly cooperative, in others partially structured species have played an important role during refolding. ${ }^{7,8}$ Now days, NMR, $\mathrm{X}$-ray crystallography, cryo-electron microscopy (cryo-EM), multiangle light scattering, and dual polarisation interferometry and circular dichroism techniques are the widely used for these studies. ${ }^{9}$

As a model for protein folding study, we selected a hypothetical protein, MTH1880 with a novel fold. ${ }^{10}$ MTH1880 is derived from $M$. thermoactotrophicum living at about $65^{\circ} \mathrm{C}$ and it has a putative $\mathrm{Ca}^{2+}$ ion binding motif, which is also typically thermal stable and undergoes reversible thermal-induced unfolding. ${ }^{10,11}$ Based on NMR analysis, we identified several putative residues which affect the native structure as well as foldingunfolding profile. The stability of MTH1880 was investigated

${ }^{\mathrm{a}}$ These authors were contributed equally. in our preliminary experiments by urea. As a result, several residues were selected as important amino acids that influence the folding profile of MTH1880 (folding-sensitive mutants). To determine the residue-specific features of MTH1880 maintaining its unique stability, we performed site directed mutagenesis, NMR and circular dichroism experiments. In this report, we present the biochemical and NMR characteristics of three folding-sensitive mutants of MTH1880. Our results will provide important information for a detailed folding-unfolding study of a novel fold protein.

\section{Experimental Procedures}

Site-directed mutagenesis and plasmid construct. The MTH1880 gene was obtained from Methanobacterium thermoautotrophicum genomic DNA by PCR amplification and it was used as a template to clone wild type protein and three different mutants (V53A(MTH1880 ${ }^{\mathrm{V} 53 \mathrm{~A}}$ ), V62A(MTH1880 ${ }^{\mathrm{V} 62 \mathrm{~A}}$ ), K67A $\left(\mathrm{MTH} 1880^{\mathrm{K} 67 \mathrm{~A}}\right)$ ). Each was digested with BamHI and XhoI and subcloned into the pET21b expression vector (Novagen Inc.) with an N-terminal hexa-histidine tag (His-tag) followed by TEV protease cleavage site. The final cloning result was confirmed by DNA sequencing.

Expression and purification. All proteins were overexpressed in E.coli strain BL21 (DE3) and transformed with pET21b/ MTH1880 plasmid constructs. Cells were grown in LB media at $37^{\circ} \mathrm{C}$ until $\mathrm{OD}_{600} 0.6$. All mutants were induced with $1 \mathrm{mM}$ isopropyl $\beta$-D-thiogalactoside (IPTG) for 20 hours at $25^{\circ} \mathrm{C}$. The 
cells were harvested by centrifugation $(6000 \times \mathrm{g}$ for $30 \mathrm{mini}-$ utes, $4{ }^{\circ} \mathrm{C}$ ), resuspended in lysis buffer $(25 \mathrm{mM}$ sodium phosphate, $300 \mathrm{mM} \mathrm{NaCl}, \mathrm{pH} 8.0)$, lysed by the sonicator and centrifuged $\left(14000 \times \mathrm{g}\right.$ for 30 miniutes, $\left.4{ }^{\circ} \mathrm{C}\right)$. The supernatant was loaded onto an Ni-NTA affinity column (Qiagen) previously equilibrated with lysis buffer. After the column was washed with $30 \mathrm{mM}$ imidazole washing buffer, MTH1880 proteins were eluted with $300 \mathrm{mM}$ imidazole elution buffer. Then, we did dialysis of eluted proteins to dilute imidazole concentration and TEV protease treatment to eliminate His-tag for 12 hours at $25{ }^{\circ} \mathrm{C}$. After TEV cleavage, the proteins were purified through $\mathrm{Ni}^{2+}$ NTA affinity chromatography again.

Preparation of labeled proteins. Uniformly ${ }^{15} \mathrm{~N}$-labeled target proteins for ${ }^{1} \mathrm{H}^{-15} \mathrm{~N}$ HSQC spectra were prepared in $200 \mathrm{~mL}$ minimal M9 media containing $0.01 \%$ ampicillin, $200 \mu \mathrm{L}$ thiamin, $2 \mathrm{~g}$ D-glucose, $0.2 \mathrm{~g}{ }^{15} \mathrm{NH}_{4} \mathrm{Cl}$ (Cambridge Isotope Laboratories, Inc) as the only source of nitrogen. When the $\mathrm{OD}_{600}$ of the cells reached to 0.6 , induction carried out by adding $1 \mathrm{mM}$ isopropyl $\beta$-D-thiogalactoside (IPTG). Cells were harvested after $20 \mathrm{hrs}$ and target proteins were purified as described above. ${ }^{15} \mathrm{~N}$-labeled samples for NMR spectroscopy were dissolved in NMR buffer containing $25 \mathrm{mM}$ sodium phosphate and $300 \mathrm{mM}$ $\mathrm{NaCl}$ in $90 \% \mathrm{H}_{2} \mathrm{O} / 10 \% \mathrm{D}_{2} \mathrm{O}(\mathrm{pH} 8.0)$, and the protein concentrations were adjusted to $0.5 \mathrm{mM}$.

NMR spectroscopy. All NMR spectra were measured at $309 \mathrm{~K}$ on a Bruker AVANCE DRX500 spectrometer equipped with a pulse-field gradient triple-resonance probe. Proton $1 \mathrm{D}-\mathrm{NMR}$ and $2 \mathrm{D}{ }^{1} \mathrm{H}-{ }^{15} \mathrm{~N} \mathrm{HSQC}{ }^{12-14}$ experiments were performed on [U${ }^{15} \mathrm{~N}$ ]-labeled MTH1880 wild type and mutant proteins. All data were processed with NMRPipe ${ }^{15}$ and analyzed with the Sparky program.

Circular dichroism. CD spectra were recorded on JASCO J-810 spectropolarimeter (Jasco, Tokyo, Japan) calibrated with ammonium D-10-camphorsulfonate at $290 \mathrm{~nm}$ and equipped with a thermostatically controlled cell holder attached to water bath with an accuracy of $\pm 0.1{ }^{\circ} \mathrm{C}$. The parameters for far-ultraviolet (UV) CD measurements were used a cell of pathlength $0.1 \mathrm{~cm}$ for scanning between $250 \mathrm{~nm}-190 \mathrm{~nm}$ and collected $1 \mathrm{~nm}$ bandwidth, and a scan speed of $50 \mathrm{~nm} \cdot \mathrm{min}^{-1}$, signal-averaged over at least eight scans, and baseline corrected by subtracting a buffer spectrum. The protein concentration of the samples was $50 \mathrm{uM}$ in $25 \mathrm{mM}$ sodium phosphate buffer of $\mathrm{pH}$ 8.0. The parameters for near-UV were collected with $2 \mathrm{~nm}$ bandwidth, and a scan speed of $50 \mathrm{~nm} \cdot \mathrm{min}^{-1}$ and the wave length range was from $320 \mathrm{~nm}$ to $240 \mathrm{~nm}$. The protein concentration of the samples was $200 \mathrm{uM}$ in $25 \mathrm{mM}$ sodium phosphate buffer of $\mathrm{pH} 8.0$ and a cell of path length $1 \mathrm{~cm}$ was used. A standard noise reduction was performed for the final spectrum.

\section{Results and Discussion}

Expression and purification of MTH1880 proteins. BLAST search indicates that MTH1880 has many homologues in archea including Methanosphaera, Methanobrevibact, and Methanocaldococcus T.volcanium (Fig. 1A). Mutation sites of MTH1880 are displayed with both ribbon diagram and surface charge model (Fig. 1B and 1C). The MTH1 880 gene was obtained from M.thermoautotrophicum genomic DNA by PCR amplification and site-directed mutagenesis and subcloned into pET21b (Novagen Inc.) at the BamHI and XhoI site. This construct contains a hexahistidine tag (His-Tag) with a TEV protease recognition sequence (ENLYFQG) in the N-terminus (Fig. 1D).

Both wild type and mutant proteins of MTH1880 were successfully expressed in $250 \mathrm{~mL}$ LB media using $1 \mathrm{mM} \mathrm{IPTG}$ at $25^{\circ} \mathrm{C}$. All proteins were purified as a purity of $>95 \%$ determined by SDS-PAGE (Fig. 2A). The molecular size of the purified

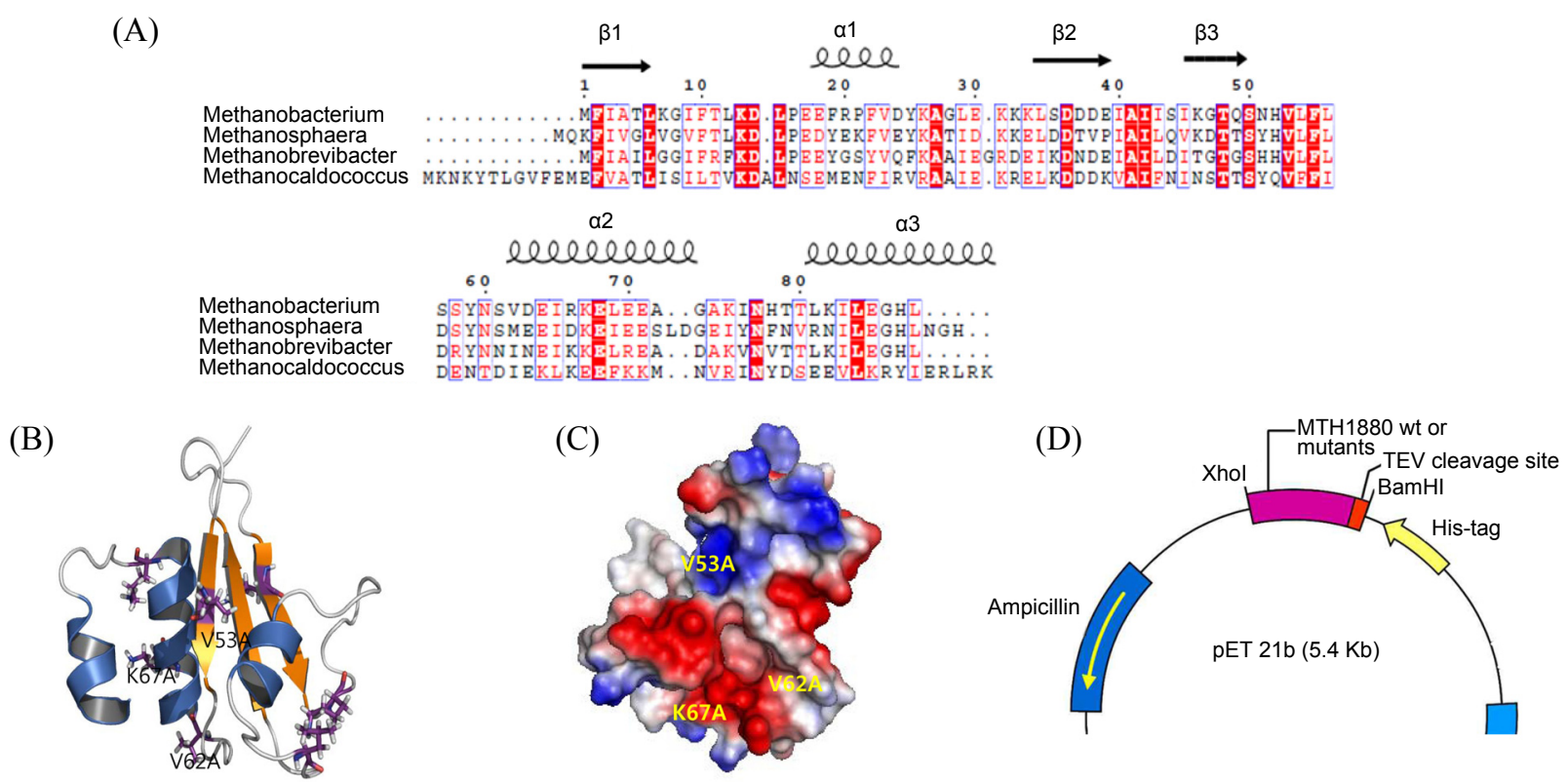

Figure 1. Sequence alignment and structure of MTH1880. (A) Pair-wise alignment of Methanobacterium thermoautotrophicum, Methanosphaera, Methanobrevibact, and Methanocaldococcus sequence using the CLUSTALW program. ${ }^{19}$ Identical parts of sequences are shown by black boxes and similar portions are shown in red box. (B) Structure of MTH1880. Mutation sites are displayed by the stick model. The ribbon diagram of the tertiary structure was drawn with PYMOL program. (C) Stereo-view of the surface charge profile of MTH1880. (D) A vector maps of E.coli expression vector containing TEV protease cleavage site for MTH1880 cloning is displayed. 
(A)
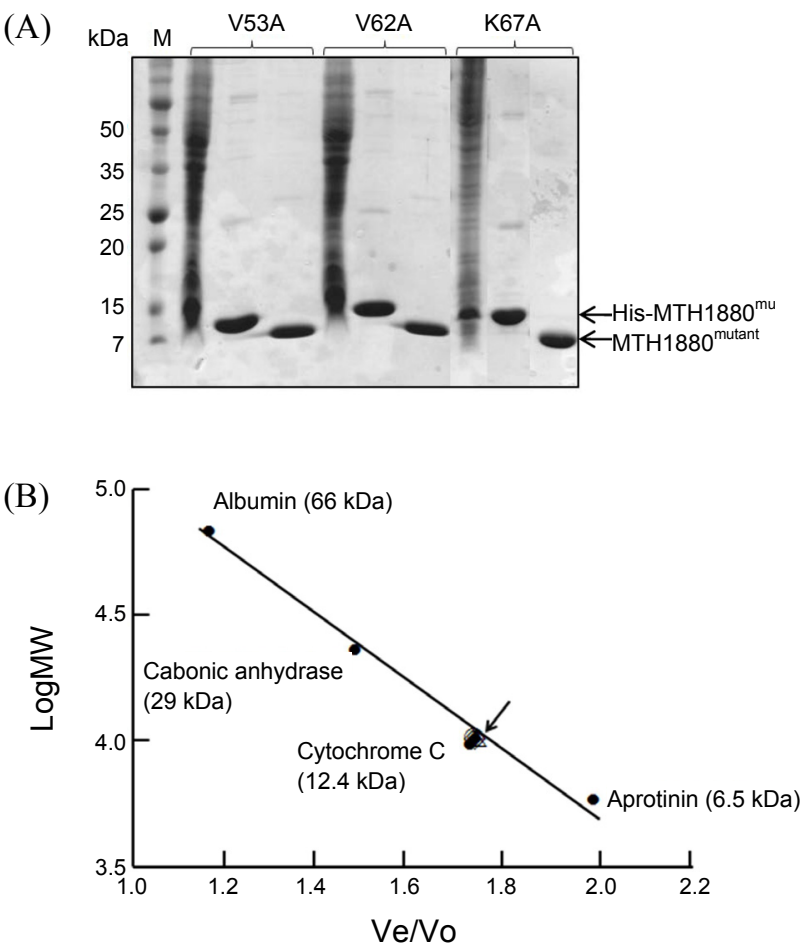

Figure 2. The SDS-PAGE for purification of MTH1880 and elution profile of the size exclusion chromatography. (A) SDS-PAGE analyses of MTH1880 wild type and mutants. The molecular weight of MTH1880 fusion protein is determined as $13 \mathrm{kDa}$ for the wild type and about 10 $\mathrm{kDa}$ after cleavage. The molecular weight markers are indicative of the protein size in each lane. (B) Elution profile of the size exclusion chromatography. Four standard markers were loaded and analyzed by Origin 7.01. MTH1 $880^{\mathrm{V} 53 \mathrm{~A}}$, MTH1 $1880^{\mathrm{V} 62 \mathrm{~A}}$ and MTH1 $1880^{\mathrm{K} 67 \mathrm{~A}}$ proteins were displayed, respectively.

fusion proteins was determined about $13 \mathrm{kDa}$ and the final molecular weight after tag cleavage was about $10 \mathrm{kDa}$, respectively. To confirm the oligomeric state of MTH1880 in solution, size exclusion chromatography has been performed using super$\operatorname{dex}^{\mathrm{TM}} 75$ column. Four proteins which are albumin $(66 \mathrm{kDa})$, carbonic anhydrase (29 kDa), cytochrome C (12 kDa), aprotinin $(6.5 \mathrm{kDa})$ were used as a standard molecular marker and the molecular weight of MTH1880 was determined as a monomer by program Origin 7.1 (Fig. 2B). The final yields of MTH1880 were $5 \mathrm{mg} \sim 9 \mathrm{mg}$ for $250 \mathrm{~mL}$ culture.

Residue-specific characteristics. The folded state of recombinant MTH1880 protein was confimed by 1D-NMR (Fig. 3A). The resonances of all mutants are similar with those of wild type from a profile of proton chemical shifts. The analysis of ${ }^{15} \mathrm{~N}-\mathrm{H}$ 2D-HSQC spectrum of wild type and mutant protein enables the detailed anaysis of the perturbation and mutational points of mutant proteins (Fig. 3B - D). The spectra of all mutant proteins show slightly pertubed resonance pattern due to point mutations. However, MTH1880 ${ }^{\mathrm{V} 53 \mathrm{~A}}$ shows dramatic changes compared with that of wild type. This result suggests that the hydrophobic residue V53 plays a critical role to make a network of hydrophobic interactions whereas K67 does not change its chemical environment of neighbouring residues, because it is located on protein surface.

Mutational effect on structural stability of MTH1880. The
(A)

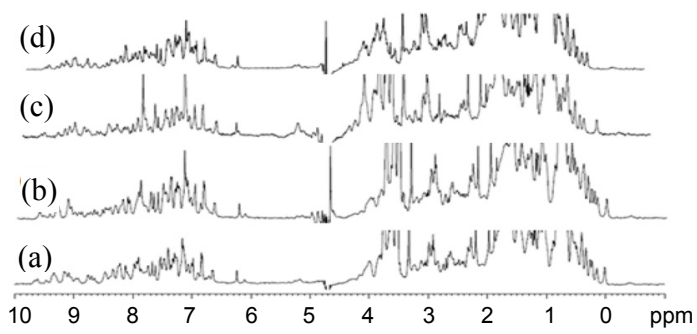

(B)

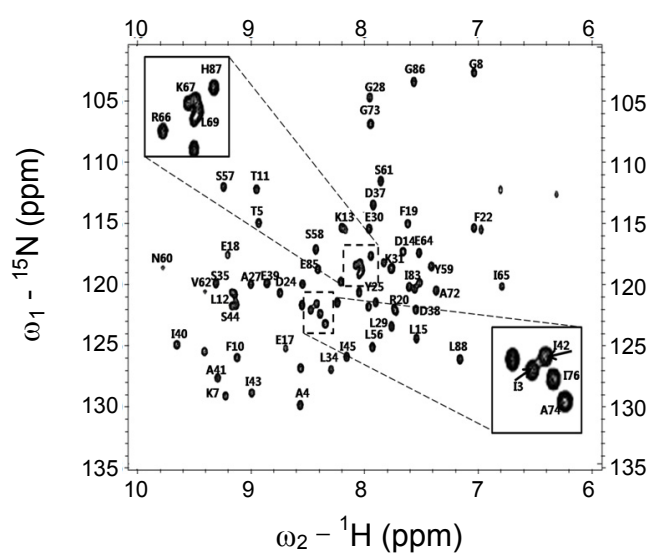

(C)

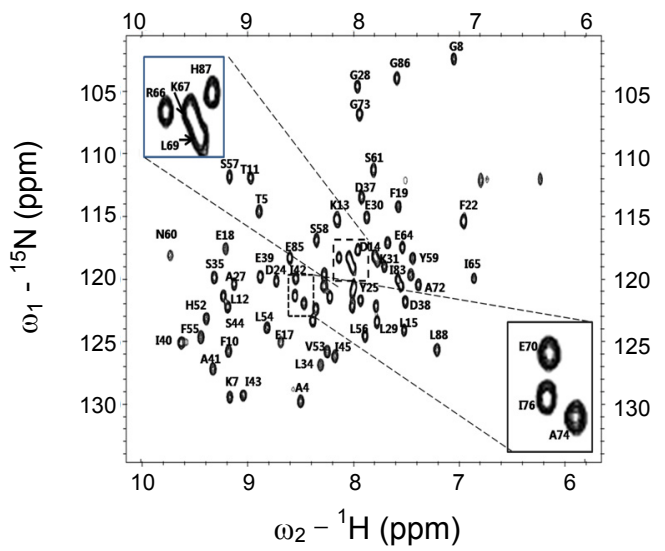

(D)

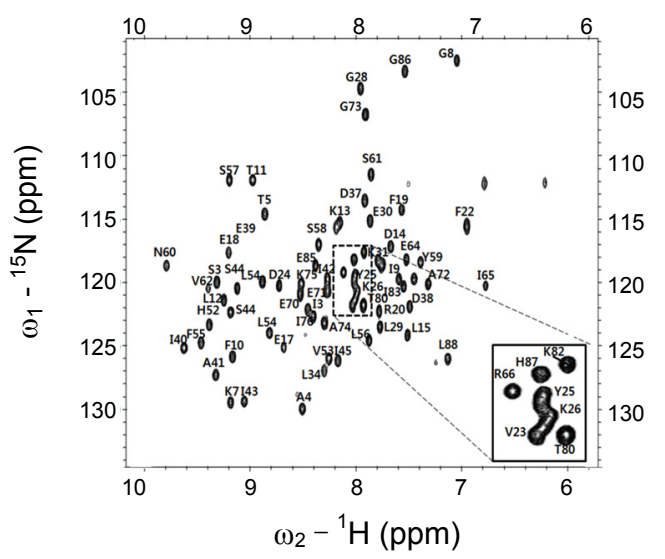

Figure 3. One-dimensional NMR and ${ }^{1} \mathrm{H}^{-15} \mathrm{~N}$ 2D-HSQC spectra of MTH1880 mutants. (A) One-dimensional NMR spectra of wild type and mutants are shown ((a) wild type (b) MTH1880 ${ }^{\mathrm{V} 53 \mathrm{~A}}$ (c) MTH$1880^{\mathrm{V} 62 \mathrm{~A}}$ (d) MTH1 $880^{\mathrm{K} 67 \mathrm{~A}}$ ). (B-D) ${ }^{\mathrm{I}} \mathrm{H}^{15} \mathrm{~N} 2 \mathrm{D}-\mathrm{HSQC}$ spectra of MTH$1880^{\mathrm{V} 53 \mathrm{~A}}$ (B), MTH1 $1880^{\mathrm{V} 62 \mathrm{~A}}$ (C) and MTH1880 ${ }^{\mathrm{K} 67 \mathrm{~A}}$ (D) are displayed, respectively. The spectra were recorded on a $0.5 \mathrm{mM}$ concentration in $25 \mathrm{mM} \mathrm{NaPi}, 0.01 \% \mathrm{NaN}_{3}, \mathrm{pH} 8.0,36{ }^{\circ} \mathrm{C}$. All NMR experiments were performed in Bruker DRX 500NHz spectrometer equipped with Cryoprobe $^{\mathrm{TM}}$. 
(A)

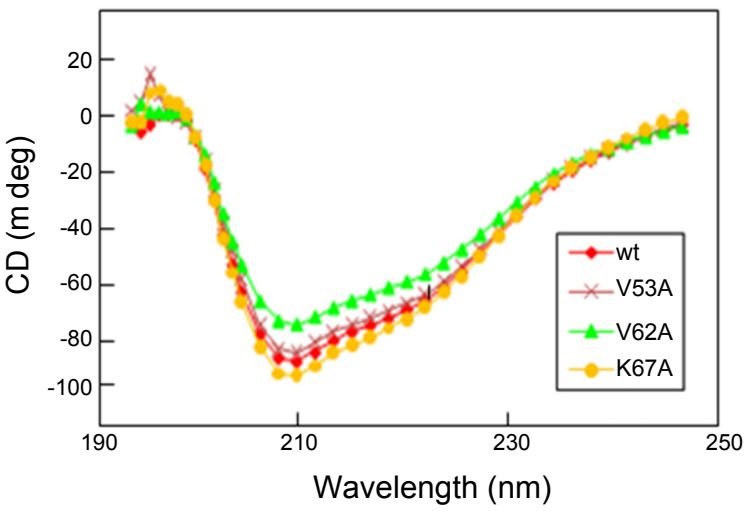

(B)

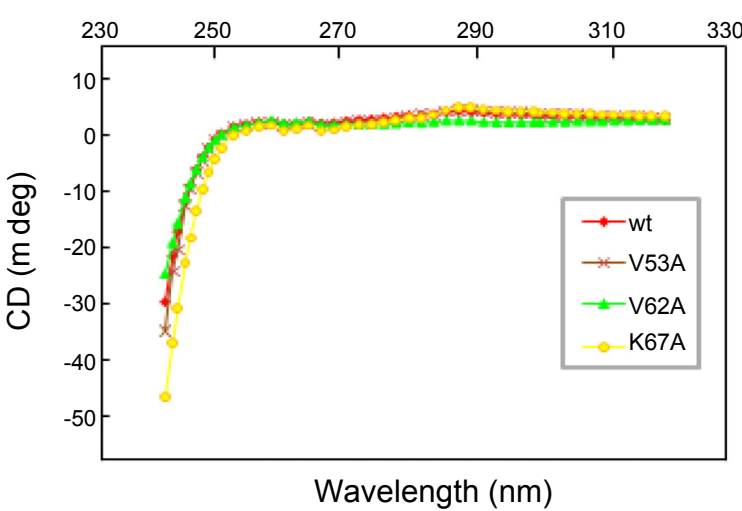

Figure 4. Circular dichroism of MTH1880 and three folding-sensitive mutants (MTH1880 ${ }^{\mathrm{V} 53 \mathrm{~A}}$, MTH1880 ${ }^{\mathrm{V} 62 \mathrm{~A}}$ and MTH1880 ${ }^{\mathrm{K} 67 \mathrm{~A}}$ ). (A) In far-UV spectral region, overall pattern of the spectra do not change much. Three mutants show similar pattern except minor structural perturbation. (B) Near-UV spectra of three mutants are displayed. All experiments were performed at $25^{\circ} \mathrm{C}$.

far-UV CD spectra for MTH1880 mutants near $210 \mathrm{~nm}$ suggest that the secondary structures do not affected by mutation (Fig. 4A). ${ }^{16-18}$ However, MTH1 $1880^{\mathrm{V} 62 \mathrm{~A}}$ and MTH $1880^{\mathrm{K} 67 \mathrm{~A}}$ exhibit different $\mathrm{CD}$ profile with that of wild type, indicating that mutantion might influence the population of secondary structural elements. Especially, MTH1880 ${ }^{\mathrm{V} 62 \mathrm{~A}}$ demonstrates a noticeable structural perturbation within secondary structures even though the residue V62 is located on the loop region (Fig. 2B). The mutation at K67 from hydrophilic to hydrophobic residue might increase helical propensity and stability.

However, the near-UV spectra of three mutants did not show any significant difference from that of wild type (Fig 4B), suggesting that a single point mutation does not affect three-dimensional fold of MTH1880.

\section{Conclusion}

A novel fold protein, MTH1880 and several mutants have been cloned and purified. We have performed biochemical analysis of MTH1880 mutants to determine the structural perturbation and stability. Data from circular dichroism and NMR spectroscopy suggest that the point mutations perturb the structural stability even though the population of secondary structures is not much changed. However, MTH $1880^{\mathrm{K} 67 \mathrm{~A}}$ where the residue is located in the middle of helix $2(\boldsymbol{\alpha} 2)$, affects its secondary structures by increasing its negative ellipticity at $210 \mathrm{~nm}$. This data provides residue-specific information to initiate further foldingunfolding study of MTH1880 and it facilitates designing folding experiments for hyper-thermopile proteins.

Acknowledgments. This work was supported by a grant (No. R01-2007-000-10161-0 to W. L.) and by the national creative research initiatives (Center for Proteome Biophysics; No. 20080061984 to I. C.) from National Research Foundation/Ministry of Education, Science and Technology of Korea. This work was also supported in part by Brain Korea 21(BK21) program.

\section{References}

1. Jung, J. W.; Lee, W. J. Biochem. Mol. Biol. 2004, 37, 28.

2. Yee, A.; Chang, X.; Pineda-Lucena, A.; Wu, B.; Semesi, A.; Le, B.; Ramelot, T.; Lee, G. M.; Bhattacharyya, S.; Gutierrez, P.; Denisov, A.; Lee, C. H.; Cort, J. R.; Kozlov, G.; Liao, J.; Finak, G.; Chen, L.; Wishart, D.; Lee, W.; McIntosh, L. P.; Gehring, K.; Kennedy, M. A.; Edwards, A. M.; Arrowsmith, C. H. Proc. Natl. Acad. Sci. USA 2002, 99, 1825

3. Wetzel, S. K.; Settanni, G.; Kenig, M.; Binz, H. K.; Plückthun, A. J. Mol. Biol. 2008, 376, 241.

4. Kim, B.; Jung, J.; Hong, E.; Yee, A.; Arrowsmith, C. H.; Lee, W. Proteins 2006, 62, 819.

5. Pande, V. S.; Grosberg, A. Yu.; Tanaka, T.; Rokhsar, D. S. Curr. Opin. Struct. Biol. 1998, 8, 68.

6. Skolnick, J. Proc. Natl. Acad. Sci. USA 2005, 102, 2265

7. Sung, Y. H.; Hong, H. D.; Cheong, C.; Kim, J. H.; Cho, J. M.; Kim, Y. R.; Lee, W. J. Biol. Chem. 2001, 276, 44229.

8. Marc, J.; Robert, L. B. Nature Structural Biology 1996, 3, 613.

9. Shi, J.; Koteiche, H. A.; McHaourab, H. S.; Stewart, P. L. J. Biol. Chem. 2006, 281, 40420.

10. Lee, C. H.; Jung, J. W.; Arrowmith, C. H.; Lee, W. Protein Sci. 2004, 13, 1148.

11. Wetzel, S. K.; Settanni, G.; Kenig, M.; Binz, H. K.; Plückthun, A. J. Mol. Biol. 2008, 376, 241.

12. Goliasnaia, N. V.; Tiurina, N. A. Mikrobiologiia 2000, 69, 805.

13. Whiteford, J. R.; Ko, S.; Lee, W.; Couchman, J. R. J. Biol. Chem. 2008, 283, 29322.

14. Thompson, J. D.; Higgins, D. G.; Gibson, T. J. Nucleic Acids Res. 1994, $22,4673$.

15. Delaglio, F.; Grzesiek, S.; Vuister, G. W.; Zhu, G.; Pfeifer, J.; Bax, A. J. Biomol. NMR 1995, 6, 277.

16. Sreerama, N.; Woody, R. W. Methods Enzymol. 2004, 383, 318.

17. Kelly, S. M.; Price, N. C. Curr. Protein Pept. Sci. 2000, 1, 349-84.

18. Goliasnaia, N. V.; Tiurina, N. A. Mikrobiologiia 2000, 69, 805.

19. Thompson, J. D.; Higgins, D. G.; Gibson T. J. Nucleic Acids Res. 1994, 22, 4673. 